\title{
Determinants of Anemia Among Pregnant Women Attending Antenatal Care in Bale-Robe Town Health Facilities, Bale zone, Southeast Ethiopia: A Case- Control Study
}

\section{Mohammed Hasen Badeso ( $\sim$ direhasen@gmail.com )}

1. Public Health Emergency Management Coordinator, East Bale Zonal Health Department, Ginnir, Ethiopia https://orcid.org/0000-0002-4668-9638

\section{Falaho Sani Kalili}

2. Negelle Borena Health Science College, Oromia Regional state, Negelle Borena, Ethiopia https://orcid.org/0000-0003-1228-5675

Mohammed Seid Abdulle

3. Public Health Emergency Management, West Hararge Zonal Health Department, Chiro, Ethiopia

\section{Research Article}

Keywords: Anemia, Pregnancy, Antenatal clinic, Case Control, Bale-Robe

Posted Date: November 8th, 2021

DOI: https://doi.org/10.21203/rs.3.rs-1058475/v1

License: (c) (i) This work is licensed under a Creative Commons Attribution 4.0 International License.

Read Full License 


\section{Abstract}

Introduction

In Ethiopia, the prevalence of anemia in pregnant women differs geographically and ranged from 15.8$56.8 \%$. The objective of this study is to identify the determinants of anemia among pregnant women attending antenatal care in health facilities of Bale-Robe Town, Southeast Ethiopia.

Methods

A facility-based case-control study was conducted in Bale-Robe hospital and Baha-biftu health center in Bale-Robe, Southeast Ethiopia. A total of 282 pregnant women participated in the study (141 cases and 141 controls). Cases were pregnant women with altitude-adjusted hemoglobin value $<11.0 \mathrm{~g} / \mathrm{dl}$ at the first and third trimesters, and $<10.5 \mathrm{~g} / \mathrm{dl}$ at the second trimester. Controls were pregnant women with hemoglobin value $\geq 11.0 \mathrm{~g} / \mathrm{dl}$ at first and third trimesters and $\geq 10.5 \mathrm{~g} / \mathrm{dl}$ at the second trimester. A structured and pretested questionnaire was used to collect data. A multivariable logistic regression analysis was applied to assess the determinants of anemia. Determinants were categorized as sociodemographic and economic, obstetric and medical, and dietary intake and behavioral.

Results

Housewife occupation ( $A O R=2.1,95 \% \mathrm{Cl}=1.12-3.92)$, prolonged menstrual bleeding ( $A O R=2.33,95 \%$ $\mathrm{Cl}=1.38-3.92)$ and undernutrition ( $\mathrm{AOR}=4.03,95 \% \mathrm{Cl}=1.38-11.83$ ) were factors significantly associated with anemia in pregnant women.

Conclusion

Housewife occupation, prolonged menstrual bleeding, and malnutrition were the determinants of anemia in pregnant women. Hence, anemia prevention and control strategy in pregnant women should include adequate dietary intake, and strengthening nutritional counseling for pregnant women during antenatal care is also required by the health care provider.

\section{Background}

Anemia in pregnant women is a common public health problem worldwide. It affects $38.2 \%$ of pregnant women globally, $48.7 \%$ in Southeast Asia, and $46.3 \%$ in Africa. ${ }^{1}$ Even though, anemia in pregnant women is a global public health problem, its burden is more substantial in developing countries. ${ }^{12}$ Anemia in pregnant women has multiple adverse outcomes for both mothers and infants, including postpartum hemorrhage, cardiac failure, less exercise tolerability, thromboembolic problems, spontaneous abortion, puerperal infection, placenta previa, maternal mortality, preterm delivery, low birth weight, and prenatal death. $^{2}$ 
Neonates of anemic mothers are born with reduced iron stores and at high risk of developing irondeficiency anemia, which leads to long-term effects such as; neurophysiologic and poor cognitive-motor development of children. ${ }^{3}$ Worldwide, it has been reported that anemia contributes to more than 591,000 prenatal deaths and 115,000 maternal deaths in a year. ${ }^{4}$ Approximately $20 \%$ of maternal death is due to anemia and its majority occur in developing countries. ${ }^{5}$

In developing countries, pregnant women start pregnancy with already reduced body stores of iron. This is mainly due to repeated infections, poor nutritional intake, frequent pregnancies, and menstrual blood loss. Besides this, it is also related to socioeconomic conditions, health-seeking behaviors, and lifestyles across different cultures. ${ }^{67}$

In Ethiopia, several studies showed that the prevalence of anemia in pregnant women varies geographically and ranged from $15.8-56.8 \% .{ }^{8-12}$ Nearly one-third of pregnant women $(31.66 \%)$ in Ethiopia has anemia according to a systematic review study conducted in Ethiopia. ${ }^{8}$

Currently in Ethiopia, different services are undertaken during antenatal care to prevent anemia during pregnancy which includes, nutritional interventions, iron, and folic acid supplementation and deworming. ${ }^{13}$ Despite many efforts made by the stakeholders and government, anemia in pregnant women is still a major public health problem. The prevalence of anemia varies within and between regions. ${ }^{101114-18}$ This suggests a need for local data to identify the determinants and address the problem. Therefore, the focus of this study was to identify the determinants of anemia among pregnant women attending antenatal care in the health facilities of Bale-Robe town, Southeast Ethiopia.

\section{Methods}

\section{Study setting and period}

The study was conducted from March 20 to June 2, 2019, among pregnant women attending antenatal care in the Bale-Robe Town health facilities. Bale-Robe town is the capital of the Bale zone and is located $430 \mathrm{~km}$ from Addis Ababa, the capital of Ethiopia. According to the town administrative health office, the total population of the town was 148,089 in the year 2019 , of whom $72,860(49.2 \%)$ are females. The town is found at an altitude of 2492 meters above sea level and there is one general public hospital, one public health center and nine private clinics in the town. The routine focused antenatal care service is provided at the public health facilities in the town.

\section{Study design and population}

A facility-based case-control study was conducted among pregnant women who attend antenatal care in Bale-Robe town health facilities. Cases were pregnant women with altitude-adjusted hemoglobin value < $11.0 \mathrm{~g} / \mathrm{dl}$ at the first and third trimesters, and $<10.5 \mathrm{~g} / \mathrm{dl}$ at the second trimester. Controls were pregnant 
women with an altitude-adjusted hemoglobin value $\geq 11.0 \mathrm{~g} / \mathrm{dl}$ at first and third trimesters and $\geq 10.5$ $\mathrm{g} / \mathrm{dl}$ at the second trimester. ${ }^{19}$ Pregnant women who attend antenatal care in the health facilities of BaleRobe town during their $1^{\text {st }}$ visit, irrespective of their trimester, and those who are residents in the town for a minimum of six months were included in the study. However, women who were severely ill during data collection and those already talking the ferrous sulfate were excluded from the study.

\section{Sample size and sampling techniques}

The sample size was calculated by Epi Info version 7. 1 software using a formula for an unmatched casecontrol study. The calculation was made for several determinants of anemia among pregnant women from previous studies by considering $95 \%$ confidence level, $80 \%$ power, a case-to-control ratio of $1: 1$. The largest sample size was obtained using the proportion of pregnant women who had anemia and not consuming chicken meat at least once per week (91.1\%) and an Adjusted odds ratio (AOR) of 2.88. ${ }^{20}$ Thus, after considering $5 \%$ non-response rate, a total of 282 participants ( 141 cases and 141 controls) were included in the study.

There are two public health facilities and nine private clinics in Bale-Robe town. Of these, two public health facilities (one general hospital and one health center) were included in the study considering the routine focused antenatal care service provision, which is provided only at the public health facilities. The number of the study subjects were allocated to both facilities proportional to their average first visit attendants per month by referring to the antenatal care registration books in both facilities. Thus, the number of monthly antenatal care attendants was 230 in the hospital and 60 in the health center. Accordingly, 238 study subjects were allocated to Bale-Robe General Hospital and 44 participants to Baha-Biftu Health Center. The consecutive sampling method was used to select the study participants.

\section{Data collection procedures}

Data were collected using a structured questionnaire adapted from literatures. ${ }^{57-10}$ 14-20 Data were collected by eight health professionals (four BSc nurses and four BSc laboratory technicians) under the supervision of two supervisors. The study subjects were identified as cases and controls based on hemoglobin level measurement, then the supervisor send to the data collectors. The questionnaire was categorized into three groups of characteristics such as; sociodemographic and economic characteristics, obstetric and medical characteristics, and dietary intake and behavioral.

\section{Measurements}

Blood hemoglobin level was determined using hemocue 201 following standard operation procedures ${ }^{19}$. The hemoglobin cutoff value was adjusted for the altitude of Bale-Robe town (2492 meters) using WHO criteria. ${ }^{21} \mathrm{~A}$ stool sample was collected from each study subject using a leak-proof stool cup and then 
stool wets mount as prepared using saline and/or iodine solution. Then, microscopically examined for identification of intestinal parasites. HIV test was conducted following the current testing algorism using the rapid test kit. Dietary diversity was measured using the Dietary Diversity Score (DDS), a tool adapted from Food and Agricultural Organization for measuring individual dietary diversity. ${ }^{22}$ The DDS was determined by asking each study participant to list all the food items consumed in the last 24 hours. Once the recall was finished, the participant was asked for the food group that was not stated. The food items were categorized into nine food groups. The dietary diversity score is the sum of food groups and ranges from 1-9.22 The mean upper arm circumference (MUAC) was measured to assess malnutrition in pregnant women using $\mathrm{WHO}$ standardized measuring tape. ${ }^{23}$

\section{Data quality control}

The questionnaire was translated to the local language Afan Oromo, and then back-translated to English for consistency (additional file 1). The questionnaire was pre-tested on $5 \%$ of the sample size (14 participants) at Goba Referral Hospital and necessary revision was made accordingly. The supervisors and data collectors were trained for two days. The laboratory reagents were regularly monitored for proper storage. On daily basis, the supervisors have strictly checked the consistency and completeness of data collected. Furthermore, the principal investigator checked data for consistency and completeness before data entry.

\section{Data analysis procedures}

The questionnaire was coded and entered using Epi Data. The data cleaning and analysis were done by SPSS version 23 software. Kolmogorov-Smirnov test was used to check the normal distribution of continuous variables. The outcome variable which is hemoglobin level was adjusted for Bale-Robe town altitude by subtracting $1.3 \mathrm{~g} / \mathrm{dl}$ from the observed hemoglobin level. ${ }^{21}$ Descriptive statistics were computed, and the categorical variables were cross-tabulated with the outcome variable, and the findings were described by frequencies and proportions for the cases and control group. The reliability of items of the scale for dietary diversity score was assessed using Cronbach's alpha.

Bivariable logistic regression was performed and variables with $P$-value less than 0.25 were transferred to multivariable logistic regression to identify the determinants of anemia. Variables with $P$-value $<0.05$ in multivariable logistic regression were considered statistically significant. The strength of association was described using an adjusted odds ratio along with its $95 \%$ confidence interval. Multicollinearity test was done using variance inflation factor and no collinearity exists between explanatory variables. The model

goodness of the test was checked by Hosmer-Lemeshow goodness of the fittest ( $P$-value $=0.81)$.

\section{Operational definition}




\section{Altitude adjusted hemoglobin level}

Hemoglobin value adjusted for altitude $<11.0 \mathrm{~g} / \mathrm{dl}$ at first and third trimesters and $<10.5 \mathrm{~g} / \mathrm{dl}$ at second trimester were used to define anemia. ${ }^{19}$

\section{Dietary diversity}

Adequate dietary diversity is considered when the DDS is $\geq 4$ and inadequate dietary diversity is the DDS below $4 .^{22}$

\section{Malnutrition}

The mean upper arm circumference measurement below 23 centimeters. ${ }^{23}$

\section{Alcohol consumption}

Current alcohol drinker is considered if a woman consumed more than 14 standard drinks of alcohol per week, and ever alcohol drinker is considered if they had consumed alcohol at least once in their life time. $^{24}$

\section{Results}

\section{Sociodemographic and economic characteristics}

A total of 281 pregnant women (141 cases and 141 controls) were recruited in the study. The response rate was $100 \%$. The median (interquartile range) age of the participants was 28 years (IQR $=25-31$ years), and ranged from 18-39 years for cases and 19-40 years for controls. Fifty-three (37.6\%) of the cases and $63(44.7 \%)$ of the controls were found between 25-29 years. More than three-fourth the cases, 109 (77.3\%) and $111(78.7 \%)$ of controls were attended formal education. The occupational status of nearly to two-third of the cases, $89(63.1 \%)$ and only $60(42.6 \%)$ of the controls were housewives. The average monthly family income for three-fourth of the cases, $106(75.2 \%)$ and $106(75.2 \%)$ of the controls were above 2000 Ethiopian birr (Table 1). 
Table 1

Bivariable logistic regression of socio-demographic and economic characteristics among pregnant mothers attending antenatal care in Bale-Robe town health facilities, Southeast Ethiopia, March 20 to June 02, 2019.

\begin{tabular}{|c|c|c|c|c|c|}
\hline Characteristics & & $\begin{array}{l}\text { Cases, n=141 } \\
(\%)\end{array}$ & $\begin{array}{l}\text { Controls, } n=141 \\
(\%)\end{array}$ & COR $(95 \% \mathrm{Cl})$ & $\begin{array}{l}P \\
\text { value }\end{array}$ \\
\hline \multirow[t]{6}{*}{ Age groups } & $15-19$ & $8(5.7)$ & $11(7.8)$ & \multirow{2}{*}{$\begin{array}{l}0.57(0.19- \\
1.71)\end{array}$} & 0.32 \\
\hline & $20-24$ & $26(18.4)$ & $24(17)$ & & 0.69 \\
\hline & $25-29$ & 53 (37.6) & $63(44.7)$ & $\begin{array}{l}0.85(0.37- \\
1.94)\end{array}$ & 0.25 \\
\hline & $30-34$ & $31(22)$ & $25(17.7)$ & $\begin{array}{l}0.67(0.32- \\
1.35)\end{array}$ & \multirow[t]{3}{*}{0.94} \\
\hline & $\geq 35$ & 23 (16.3) & $18(12.8)$ & $\begin{array}{l}0.97(0.43- \\
2.18)\end{array}$ & \\
\hline & & & & 1 & \\
\hline \multirow[t]{5}{*}{ Religion } & Orthodox & $44(31.2)$ & 55 (39) & \multirow{2}{*}{$\begin{array}{l}0.4(0.09- \\
1.69)\end{array}$} & 0.21 \\
\hline & Protestant & $24(17)$ & $17(12.1)$ & & 0.65 \\
\hline & Muslim & $67(47.5)$ & $66(46.8)$ & $\begin{array}{l}0.71(0.16- \\
3.22)\end{array}$ & 0.35 \\
\hline & Catholic & $6(4.3)$ & $3(2.1)$ & $\begin{array}{l}0.51(0.12- \\
2.12)\end{array}$ & \\
\hline & & & & 1 & \\
\hline \multirow[t]{2}{*}{ Marital status } & Married & 134 (95) & $136(96.5)$ & \multirow{2}{*}{$\begin{array}{l}0.7(0.22- \\
2.27)\end{array}$} & \multirow[t]{2}{*}{0.56} \\
\hline & Divorce & $7(5)$ & $5(3.5)$ & & \\
\hline \multirow{5}{*}{$\begin{array}{l}\text { Educational } \\
\text { status }\end{array}$} & llliterate & $15(106)$ & $12(85)$ & \multirow{2}{*}{$\begin{array}{l}1.27(0.57- \\
2.84)\end{array}$} & 056 \\
\hline & Non formal & $17(121)$ & $18(128)$ & & \multirow{4}{*}{0.92} \\
\hline & & & & \multirow{2}{*}{$\begin{array}{l}0.96(0.47- \\
1.96)\end{array}$} & \\
\hline & Formal & 109 (77.3) & 111 (78.7) & & \\
\hline & & & & 1 & \\
\hline \multirow[t]{5}{*}{ Occupation } & Merchant & 15 (10.6) & $27(19.1)$ & \multirow{2}{*}{$\begin{array}{l}0.82(0.38- \\
1.77)\end{array}$} & 0.61 \\
\hline & House wife & $89(63.1)$ & 60 (42.6) & & 0.006 \\
\hline & Student & $5(3.5)$ & $7(5.0)$ & $\begin{array}{l}2.18(1.25- \\
3.79)\end{array}$ & \multirow[t]{3}{*}{0.94} \\
\hline & Employed & 32 (22.7) & 47 (33.3) & $\begin{array}{l}1.05(0.31- \\
3.59)\end{array}$ & \\
\hline & & & & 1 & \\
\hline
\end{tabular}




\begin{tabular}{|llllll|}
\hline Characteristics & & $\begin{array}{l}\text { Cases, } \mathbf{n = 1 4 1} \\
(\%)\end{array}$ & $\begin{array}{l}\text { Controls, } \mathbf{n = 1 4 1} \\
(\%)\end{array}$ & COR (95\%Cl) & $\begin{array}{l}\mathbf{P} \\
\text { value }\end{array}$ \\
\hline Monthly income & $\leq 1500$ ETB & $14(9.9)$ & $13(9.2)$ & $1.08(0.48-$ & 0.87 \\
& $1501-2000$ & $21(14.9)$ & $22(15.6)$ & $2.40)$ & 0.89 \\
& ETB & $106(75.2)$ & $106(75.2)$ & $0.96(0.49-$ & $1.84)$ \\
& & & 1 & \\
\hline
\end{tabular}

\section{Obstetric and medical characteristics}

Half of the cases, $74(52.5 \%)$ and $67(47.5 \%)$ of the controls were multigravida. Only eleven $(7.8 \%)$ of the cases and $9(6.4 \%)$ of the control had more than four children. More than three fourth of the cases, 118 (83.7\%) and 114 (80.9\%) of the controls had the previous history of contraceptive use. Half of the cases, $73(51.8 \%)$ had history of menstrual flow for more than six days, while only $40(28.4 \%)$ among the controls. Nearly half of the cases, $64(45.4 \%)$ and 61 (43.3\%) of the controls were in the second trimester pregnancy. Fifteen $(10.6 \%)$ of the cases and $6(4.3 \%)$ of the controls had history of blood loss during the current pregnancy. Intestinal parasites were identified in only nine $(6.4 \%)$ of the cases and five $(3.5 \%)$ of the controls. Among the participants, only $6(4.3 \%)$ of the cases and $6(2.8 \%)$ of the controls reported history of chronic illness (Table 2).

Table 2: Obstetric and medical characteristics of pregnant mothers attending antenatal care in Bale-Robe town health facilities, Southeast Ethiopia, March 20 to June 02, 2019. 


\section{Characteristics}

$\begin{array}{llll}\text { Cases, } & \text { Controls, } & \text { COR } & P \\ n=141(\%) & n=141(\%) & (95 \% \mathrm{Cl}) & \text { value }\end{array}$

\begin{tabular}{|c|c|c|c|c|c|}
\hline \multirow[t]{3}{*}{ Gravida } & Primigravida & $67(47.5)$ & $74(52.5)$ & \multirow{2}{*}{$\begin{array}{l}0.82 \\
(0.51- \\
1.31)\end{array}$} & \multirow[t]{3}{*}{0.41} \\
\hline & \multirow[t]{2}{*}{ Multigravida } & $74(52.5)$ & $67(47.5)$ & & \\
\hline & & & & 1 & \\
\hline \multirow[t]{2}{*}{ Number of children } & $\leq 4$ children & $130(92.2)$ & $132(93.6)$ & 1 & \\
\hline & $>4$ children & $11(7.8)$ & $9(6.4)$ & $\begin{array}{l}1.24(0.5- \\
3.1)\end{array}$ & 0.64 \\
\hline \multirow[t]{3}{*}{ History of contraceptive use } & Yes & $118(83.7)$ & $114(80.9)$ & \multirow{2}{*}{$\begin{array}{l}1.22 \\
(0.67- \\
2.24)\end{array}$} & \multirow[t]{3}{*}{0.53} \\
\hline & No & $23(16.3)$ & $27(19.1)$ & & \\
\hline & & & & 1 & \\
\hline \multirow[t]{3}{*}{ Menstrual flow in days } & $>6$ days & $73(51.8)$ & $40(28.4)$ & \multirow{2}{*}{$\begin{array}{l}2.71 \\
(1.66- \\
4.44)\end{array}$} & \multirow[t]{3}{*}{0.0001} \\
\hline & $\leq 6$ days & $68(48.2)$ & $101(71.6)$ & & \\
\hline & & & & 1 & \\
\hline \multirow[t]{4}{*}{ Pregnancy Trimester } & First & $58(41.1)$ & $63(44.7)$ & \multirow{2}{*}{$\begin{array}{l}0.82 \\
(0.39- \\
1.74)\end{array}$} & 0.61 \\
\hline & Second & $64(45.4)$ & $61(43.3)$ & & \multirow[t]{3}{*}{0.87} \\
\hline & Third & $19(13.5)$ & $17(12.1)$ & $\begin{array}{l}0.94 \\
(0.45- \\
1.97)\end{array}$ & \\
\hline & & & & 1 & \\
\hline
\end{tabular}

\begin{tabular}{llllll}
$\begin{array}{l}\text { History of blood loss during } \\
\text { pregnancy }\end{array}$ & Yes & $15(10.6)$ & $6(4.3)$ & $\begin{array}{l}2.68 \\
(1.01-\end{array}$ & 0.048 \\
& No & $126(89.4)$ & $135(95.7)$ & $\begin{array}{l}7.12) \\
1\end{array}$ & \\
& & & & 0.28 \\
\hline Intestinal parasite & Yes & $9(6.4)$ & $5(3.5)$ & $\begin{array}{l}1.86 \\
(0.61-\end{array}$ & \\
& No & $132(93.6)$ & $136(96.5)$ & $5.68)$ & \\
& & & & 1 & 0.56 \\
HIV status & Positive & $7(5)$ & $5(3.5)$ & 1.42 & $(0.44-$ \\
& Negative & $134(95)$ & $136(96.5)$ & $4.59)$ & \\
& & & & 1 & \\
History of chronic illness & Yes & $6(4.3)$ & $4(2.8)$ & 1.52 & 0.52 \\
& No & $135(95.7)$ & $137(97.2)$ & $5.52)$ & \\
& & & & 1
\end{tabular}




\section{Dietary and behavioral characteristics}

More than three fourth, $122(86.5 \%)$ of the cases and $113(80.1 \%)$ of the controls were drinking coffee immediately after meal. Only $10(7.1 \%)$ of the cases and $13(9.2 \%)$ of the controls had history of alcohol consumption. More than half of the cases, 84 (59.6\%) and two-third of the controls, 98 (69.5\%) were consuming adequate dietary diversified food. Regarding nutritional status of the participants, more than three fourth of the cases 123 (87.2\%) and nearly all controls 136 (96.5\%) were well-nourished (Table 3).

Table 3: Dietary and behavioral characteristics of pregnant mothers attending antenatal care in Bale-Robe town health facilities, Southeast Ethiopia, March 20 to June 02, 2019.

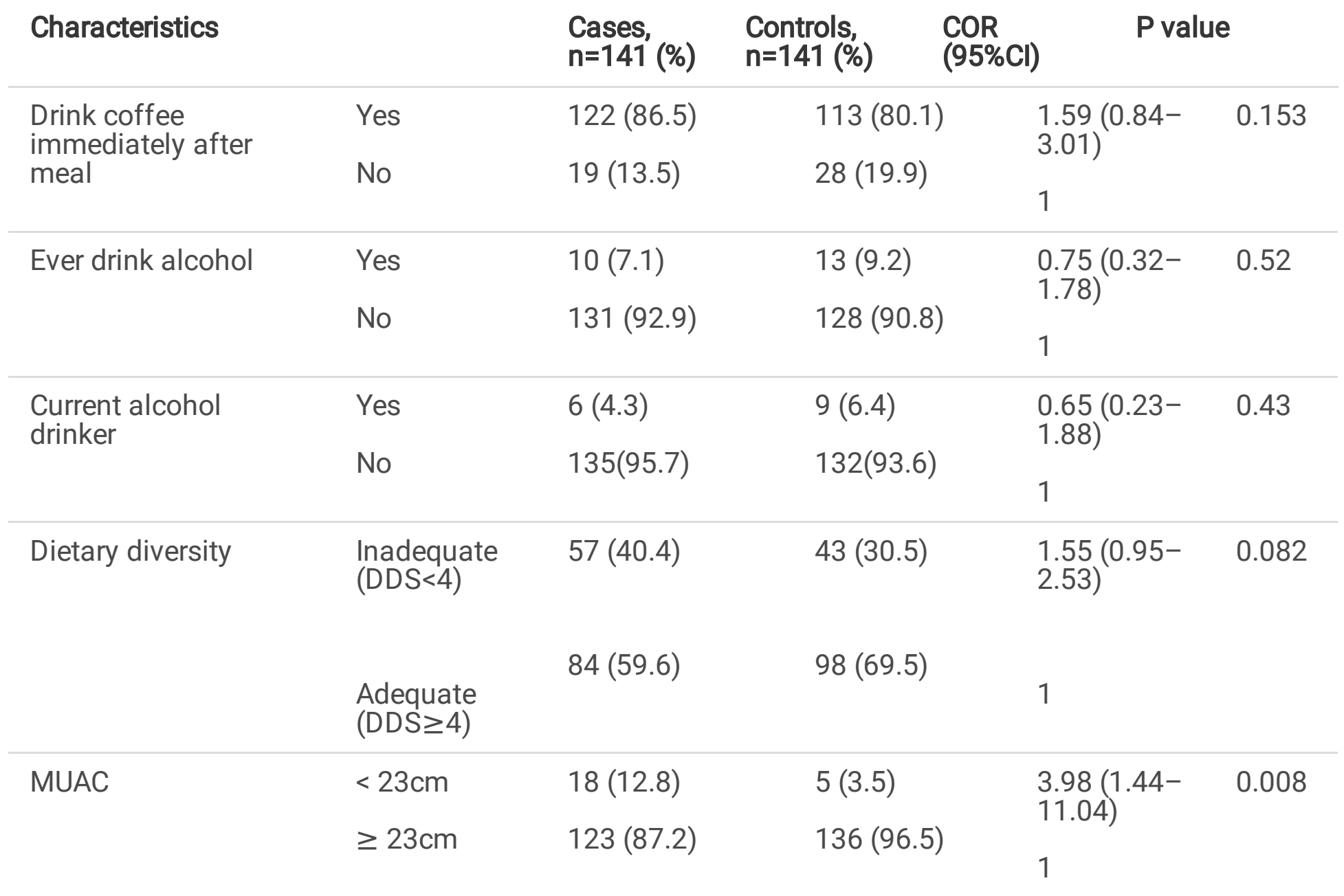

COR, Crude odds ratio

\section{Bivariable Analysis}


Variables having $P$-value $<0.25$ in bivariable logistic regression were transferred to multivariable logistic regression. Accordingly, religion and occupational status from sociodemographic and economic characteristics (Table 1), the duration of menstrual flow and history of blood loss during pregnancy from obstetric and medical characteristics (Table 2), drinking coffee immediately after meal, dietary diversity and nutritional status from dietary and behavioral characteristics (Table 3) were selected as candidate variables for multivariable logistic regression.

\section{Determinants of anemia among pregnant women}

In multivariable logistic regression, three variables (occupational status, duration of menstrual flow, nutritional status) were significantly associated with anemia among pregnant women. Pregnant women whom their occupational status was housewives were two times more likely to have anemia compared to the employed women $(A O R=2.1,95 \% \mathrm{Cl}=1.12-3.92)$. The odds of developing anemia among pregnant women who had prolonged previous menstrual period for more than 6 days were two times higher compared to those mothers with less than six days menstrual bleeding (AOR=2.33, 95\% $\mathrm{Cl}=1.38-3.92)$. Similarly, pregnant women who had malnutrition were four times more likely to have anemia during pregnancy as compared to well-nourished ( $\mathrm{AOR}=4.03,95 \% \mathrm{Cl}=1.38-11.83)$ (Table 4).

Table 4: Bivariable and Multivariable logistic regression analysis showing factors associated with anemia among pregnant mothers attending antenatal care in Bale-Robe town health facilities, Southeast Ethiopia, March 20 to June 02, 2019.

\begin{tabular}{|c|c|c|c|c|c|}
\hline Characteristics & & $\begin{array}{l}\text { Cases, } \\
\mathrm{n}=141 \text { (\%) }\end{array}$ & $\begin{array}{l}\text { Controls, } \\
\mathrm{n}=141 \text { (\%) }\end{array}$ & $\begin{array}{l}\text { COR } \\
(95 \% \mathrm{Cl})\end{array}$ & AOR (95\%Cl) \\
\hline \multirow[t]{4}{*}{ Occupation } & Merchant & 15 (10.6) & $27(19.1)$ & $\begin{array}{l}0.82(0.38- \\
.77)\end{array}$ & $\begin{array}{l}0.96(0.41- \\
2.22)\end{array}$ \\
\hline & $\begin{array}{l}\text { House } \\
\text { wife }\end{array}$ & $89(63.1)$ & $60(42.6)$ & $\begin{array}{l}2.18(1.25- \\
3.79)\end{array}$ & $\begin{array}{l}2.1(1.12- \\
3.92) *\end{array}$ \\
\hline & Student & $5(3.5)$ & $7(5.0)$ & $\begin{array}{l}1.05(0.31- \\
3.59)\end{array}$ & $\begin{array}{l}0.93(0.24- \\
3.54)\end{array}$ \\
\hline & Employed & $32(22.7)$ & 47 (33.3) & & 1 \\
\hline \multirow[t]{2}{*}{$\begin{array}{l}\text { Duration of } \\
\text { menstrual flow }\end{array}$} & $\begin{array}{r}>6 \\
\text { days }\end{array}$ & $73(51.8)$ & $40(28.4)$ & $\begin{array}{l}2.71(1.66- \\
4.44)\end{array}$ & $\begin{array}{l}2.33(1.38- \\
3.92) *\end{array}$ \\
\hline & $\begin{array}{r}\leq 6 \\
\text { days }\end{array}$ & 68 (48.2) & 101 (76.1) & 1 & 1 \\
\hline \multirow[t]{2}{*}{ MUAC } & $<23 \mathrm{~cm}$ & $18(12.8)$ & $5(3.5)$ & $\begin{array}{l}3.98(1.44- \\
11.0)\end{array}$ & $\begin{array}{l}4.03(1.38- \\
11.83) *\end{array}$ \\
\hline & $23 \stackrel{\geq}{\mathrm{cm}}$ & $123(87.2)$ & 136 (96.5) & & 1 \\
\hline
\end{tabular}


${ }^{*} \mathrm{P}<0.01, \mathrm{COR}$, crude odds ratio; $\mathrm{AOR}$, Adjusted odds ratio

\section{Discussion}

Anemia in pregnant women increases the risk of both maternal and child morbidity and mortality, including impaired cognitive development of the children, and decrease work productivity in adults. ${ }^{25}$ Prevention and control of anemia among pregnant women are key measures to reduce the adverse effects of anemia in mothers and children. The finding of this study showed that housewife occupational status, prolonged menstrual period and malnutrition were significant determinants of anemia among pregnant women.

Housewife occupational status is found to be significantly associated with anemia in pregnant women. Pregnant women whose their occupational status was housewives were two times more likely to have anemia compared to employed women. This finding is consistent with a similar study conducted in Durame, Southern Ethiopia, ${ }^{26}$ and a study in Gondar, Northern Ethiopia, ${ }^{27}$ which reported a significant positive association between housewife occupational status and anemia in pregnant women. This might be due to the workload on housewives and financial shortage, which result in difficulty of obtaining food. Mothers with a shortage of income due to occupational status will not able to fulfill the daily dietary intake needed for pregnant women and as a result, develop anemia. ${ }^{28}$ In contrast, the study conducted in North Shoa, Ethiopia found a negative association between housewives' occupational status and anemia during pregnancy. ${ }^{14}$ This discrepancy might be due to the variation in study design. The implication of this finding is the importance of women engaging in an income-generating occupation to fulfill dietary requirements during pregnancy.

Another finding of this study is the prolonged previous menstrual bleeding, which is significantly associated with anemia. The odds of developing anemia among pregnant women who had prolonged previous menstrual bleeding for more than 6 days were two times higher compared to those mothers with less than six days of bleeding. This finding is in line with the studies conducted in Durame town, Southern Ethiopia, ${ }^{26}$ and in Mekele town, Tigray Ethiopia, ${ }^{29}$ which showed a significant association between heavy menstrual bleeding and development of anemia during pregnancy. Likewise, our finding is supported by similar studies conducted in Hawassa and Yirgalem, ${ }^{30}$ Wolayita, ${ }^{18}$ Mizantepi, ${ }^{12}$ and East Hararghe zone of Ethiopia ${ }^{5}$. This is due to the fact that prolonged menstrual bleeding results in blood loss and reduces the number of circulating red blood cells. In addition, prolonged blood loss may decrease iron levels enough to increase the risk of iron deficiency anemia. This finding implies the women with the prolonged previous menstrual bleeding need to take iron-rich food and iron supplementation during pregnancy.

Undernutrition during pregnancy is found to be significantly associated with anemia. Pregnant women who had malnutrition during pregnancy were four times more likely to have anemia as compared to wellnourished. This is consistent with the finding of studies conducted in Asosa, Western Ethiopia, ${ }^{31}$ and 
study in Gondar, Northern Ethiopia. ${ }^{28}$ Similarly, the studies conducted in Jamaica, ${ }^{32}$ and Tanzania, ${ }^{33}$ reported a positive association between undernutrition during pregnancy and anemia. Nutritional deficiency is the major contributing factor for anemia among pregnant women and this is due to undernutrition is related to iron, folate, and vitamin A and other micronutrients deficiencies. ${ }^{12} 2734$ This is due to the fact that poor dietary intake and micronutrient deficiencies due to malnutrition result in anemia because pregnancy is the most nutritional demanding. In addition, malnutrition during pregnancy is results in iron deficiency anemias as a result of inadequate dietary iron intake. This is further supported by the WHO report, which stated in developing countries, inadequate intake of dietary iron is the main cause of anemia during pregnancy. ${ }^{35}$ Our finding suggests that taking adequate dietary intake during pregnancy is required for the prevention of anemia among pregnant women.

\section{Limitations Of The Study}

The temporal relationships between explanatory variables and anemia cannot be determined, as it is a case-control study. Social desirability bias and recall bias are also other limitations of our study regarding dietary diversity, alcohol consumption and monthly income. The dietary intake could also be affected by seasonal variation. Moreover, the findings of the current research cannot be generalized to the whole community because of its institution-based nature.

\section{Conclusions}

Different factors were studied to identify the determinants of anemia among pregnant women. Housewife occupation, prolonged menstrual period and malnutrition were the determinants of anemia among pregnant women. Therefore, pregnant women with prolonged previous menstrual bleeding need to take iron-rich food and iron supplementation. Anemia prevention and control strategy in pregnant women is required to include adequate dietary intake for the prevention of anemia. Strengthening nutritional counseling for pregnant women during antenatal care is also required by the health care provider. Finally, further longitudinal studies which determine the cause of anemia in pregnant women are recommended for the researcher.

\section{Strengths And Limitations Of This Study}

- This study used hemocue 201 to determine blood hemoglobin levels following standard operating procedures.

- This study included several detailed measures of dietary, behavioral, obstetric and medical characteristics, and identified determinants that will be important in the prevention and control of anemia in pregnant women.

- The temporal relationships between explanatory variables and anemia could not be established as we have used a case-control study design. 
- Social desirability bias and recall bias might be introduced during measuring dietary diversity, alcohol consumption and monthly income.

\section{Declarations}

Contributions: MHB involved in the study design, data collection, analysis and write-up. FSK performed analysis, interpretation of data and drafted the manuscript. MSA contributed to the design, data collection and revision of the manuscript. All authors approved the final version.

Funding: This study no specific finance from any funding agency.

Competing interests: None declared.

Ethics approval: Ethical clearance was obtained from the institutional review board of Institute of Health, Jimma University (Ref.No./IHRPGD/767/2019).

Patient and Public Involvement: Written informed consent was obtained from each participant after explaining the purpose of the study. The confidentiality of information obtained from the participants was assured and the study subjects were informed that, they had full right to participate to the study. The pregnant women who had anemia and those investigated positive for intestinal parasite were linked to the health facilities antenatal care unit for treatment.

Data sharing statement: No additional data are available.

Acknowledgements: We would like to thank Jimma University and Ethiopia Field Epidemiology and laboratory Training Program for their support. We are grateful to all the study subjects who are participated in the study. We would also like to thank the Bale-Robe General Hospital and Baha-Biftu health center administration for their permission and support during data collection. We are thankful to Goba Referral Hospital for their support during pre-test. Finally, we are grateful to the data collectors and supervisors who were devoted their valuable time and cooperation.

Additional file: Additional file 1: questionnaire used for data collection.

\section{References}

1. World Health Organization. The global prevalence of anemia in 2011. Geneva: World Health Organization, 2015.

2. World Health Organization. Iron Deficiency Anaemia Assessment, Prevention and Control: A guide for progamme managers. WHO. 2001. WHO/NHD/01.3.

3. Luis $\mathrm{CR}$, Moshe $\mathrm{H}$, Anil $\mathrm{K}$, et al. Early origins of health: The role of maternal health on current and future burden of chronic noncommunicable diseases. Int. J. Gynecol. Obstet. 2011;115 (Supp 1). 
4. S. Salhan, V. Tripathi, R. Singh, et al. "Evaluation of Hematological Parameters in Partial Exchange and Packed Cell Transfusion in Treatment of Severe Anemia in Pregnancy," 2012.

5. Filagot K, Endalew Z, Yaregal A, et al. Anemia among pregnant women in Southeast Ethiopia: prevalence, severity and associated risk factors. BMC Research Notes. 2014;7:771.

6. Ks Khan, Wojdyla D, Say L, GuÈlmezoglu AM, Van Look PF. WHO analysis of causes of maternal death: a systematic review. The Lancet. 2006; 367(9516):1066-74.

7. Karaoglu L, Pehlivan E, Egri M, Deprem C, Gunes G, Genc MF, et al. The prevalence of nutritional anemia in pregnancy in an East Anatolian Province, Turkey. BMC Public Health. 2010; 10(1):1.

8. Getachew MK, Achenef AM, Abadi KB, et al. Prevalence and determinants of anemia among pregnant women in Ethiopia; a systematic review and meta-analysis. BMC Hematology. 2017;17(17).

9. Central Statistical Agency (CSA), Ethiopia and ICF. 2016. Ethiopia Demographic and Health Survey 2016. Addis Ababa, Ethiopia, and Rockville, Maryland, USA: CSA and ICF. 2016.

10. Mulugeta $M$, Zelalem A, Meseret $A$, et al. Prevalence and Predictors of Maternal Anemia during Pregnancy in Gondar, Northwest Ethiopia : An Institutional Based Cross-Sectional Study. Hindawi. 2014;9.

11. Teklit G, Ermyas B, Solomon H, et al. Magnitude and factors associated with anemia among pregnant women attending antenatal care in public health centers in central zone of Tigray region, northern Ethiopia : a cross sectional study. BMC Pregnancy and childbirth. 2018;18(433).

12. Befikadua Z, Asrat M, Abdu H, et al. Prevalence of Anemia and its Associated Factors among Pregnant Women Attending Antenatal Care (ANC) In Mizan Tepi University Teaching Hospital, South West Ethiopia. Health Science Journal. 2017;11(5):529.3.

13. Federal Democratic Republic of Ethiopia Ministry of Health. Health Sector Transformation Plan.Federal Democratic Republic of Ethiopia Ministry of Health, 2015/16-2019/20. Addis Ababa, Ethiopia, 2015.

14. Fantahun AM, Yohannes AA, Genanew TN. Socio-economic determinants of anemia in pregnancy in North Shoa Zone, Ethiopia. PLoS ONE. 2018;13(8): e0202734.

15. Million G, Delenesaw $Y$, Ketema T, et al. Anaemia and associated risk factors among pregnant women in Gilgel Gibe dam area, Southwest Ethiopia. Parasites \& Vectors. 2012;5:296.

16. Niguse 0 , Andualem M, Teshome G. Magnitude of anemia and associated risk factors among pregnant women attending antenatal care in shalla. Ethiop J Health Sci. 2013;23(2):165-173.

17. Bizuneh A, Befekadu A. Assessment of Prevalence and Risk Factors for Anemia Among Pregnant Mothers Attending Anc Clinic at Adama Hospital Medical Collage, Adama, Ethiopia. Journal of Gynecology and Obstetrics. 2018;6(3):31-39.

18. Lealem G, Asrat A, Yaregal A, Andualem M. Anemia and associated risk factors among pregnant women attending antenatal care clinic in Wolayita Sodo town, Southern Ethiopia. Ethiop J Health Sci. 2015;25(2):155-162.3. 
19. WHO. Haemoglobin concentrations for the diagnosis of anaemia and assessment of severity. Vitamin and Mineral Nutrition Information System. Geneva, World Health Organization, 2011.

20. Tadesse SE, Seid O, G/Mariam Y, et al. Determinants of anemia among pregnant mothers attending antenatal care in Dessie town health facilities, northern central Ethiopia, unmatched case -control study. PLOS ONE. 2017;12(3): e0173173.

21. Nestel P. and The INACG Steering Committee. Adjusting Hemoglobin Values in Program Surveys. 2002.

22. Food and Agriculture Organization (FAO). Guidelines for Measuring Household and Individual Dietary Diversity. Rome, Italy; 2010.

23. Ververs MT, Antierens A, Sackl,A. et al. "Which anthropometric indicators identify a pregnant woman as acutely malnourished and predict adverse birth outcomes in the humanitarian context?" PLOS Currents. 2013;5.

24. Ethiopia Public Health Institute, FMOH. Ethiopia STEPS Report on Risk Factors for NonCommunicable Disease and Prevalence of Selected NCDs. Addis Ababa, Ethiopia; 2016.

25. WHO. Focusing on anaemia: towards an integrated approach for effective anaemia control. Geneva: World Health Organization. 2004.

26. Fekede W, Mesfin K, Meseret G, Net al. Determinants of Anemia among Pregnant Women Attending Antenatal Clinic in Public Health Facilities at Durame Town : Unmatched Case Control Study. Hidawi. 2018.

27. Meseret A, Bamlaku E, Aschalew G,et al. Prevalence of anemia and associated risk factors among pregnant women attending antenatal care in Azezo Health Center Gondar town, Northwest Ethiopia. J Interdiscipl Histopathol. 2013;1(3):137-144.

28. Terefe D, Zelalem A, Amare T. Magnitude and associated factors of anemia among pregnant women in Dera District: a cross - sectional study in northwest. BMC Res. Notes. 2017;10(2017): 359.

29. Yirga $E$, Mussie A, Mengistu M, et al. Determinants of severe anemia among laboring mothers in Mekelle city public hospitals, Tigray region, Ethiopia. PLOS ONE. 2017;12(11): e0186724.

30. Belete A, Ayele AD, Biruhalem T, et al. Major Risk Factors Predicting Anemia Development during Pregnancy: Unmatched-Case Control Study. J Community Med Health Educ. 2015;5(3): 353.

31. Abera A, Haile WY, Amare T, et al. Determinants of prenatal anemia in Ethiopi. Archives of Public Health. 2017;75(2017):51.

32. Alyson MC, Dianne CS, Nelly Y, Pauline EJ. Predictors of anemia among pregnant women in Westmoreland, Jamaica. Health Care Women Int. 2011;31(7):585-598.

33. Hinderaker SG, Olsen BE, Lie RT, et al. Anemia in pregnancy in rural Tanzania: associations with micronutrients status and infections. European Journal of Clinical Nutrition. 2002;56(2002):192199.

34. World Health Organization. WHO Recommendations on antenatal care for positive pregnancy expreince. WHO Library Cataloguing-in-Publication Data. 2016. 
35. De BB, Mclean E, Egli I, et al. WHO global Database on anaemia. Geneva: WHO. 2008:1993-2005. 